\title{
SELECTING AN APPROPRIATE OCCLUSAL SCHEME WHEN FABRICATING IMPLANT-SUPPORTED FIXED DENTAL PROSTHESES: A SYSTEMATIC REVIEW
}

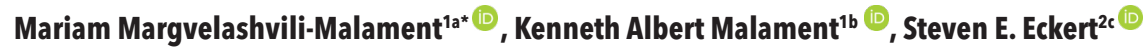 \\ 'Department of Prosthodontics' School of Dental Medicine, Tufts University, Boston, MA, USA \\ ${ }^{2}$ College of Medicine, Mayo Clinic, Rochester, MN, USA \\ aDMD, MSc, PhD, Assistant Professor; e-mail: mariam.malament@tufts.edu; ORCIDiD: https://orcid.org/0000-0002-3751-0675 \\ bDS, MSCD, Clinical Professor; e-mail: kenneth.malament@tufts.edu; ORCIDiD: https://orcid.org/0000-0002-7144-5643 \\ 'DDS, MS, Professor Emeritus; e-mail: seeckert@me.com; ORCIDiD: https://orcid.org/0000-0001-9382-7135
}

Background Dental implants are ankylosed in the bone without a periodontal ligament resulting in a lack of micro-mobility during chewing. Consequently, occlusion with dental implants may be at greater risk, specifically when the teeth come into contact in lateral excursive movements.

Objective A systematic review of the literature was performed to identify occlusal concepts that were most favorable for implant-retained fixed restorations.

Data Sources A search of the literature was conducted using PubMed and EndNote literature online software databases. Keywords were used to assist in the identification of the literature.

Study Selection The literature search identified 49 articles using PubMed and 33 articles using the authorcreated EndNote database.

Data Extraction Two occlusal concepts were identified, namely mutually protected occlusion and group function unilateral occlusion. None of the articles demonstrated clear scientific evidence to identify superiority of one concept over the other.

Data Synthesis Based upon the systematic review of the literature, no scientific evidence was identified favoring any specific occlusal concept.

\section{KEYWORDS}

Occlusion; Dental Implants; Implant Supported Fixed Restoration; Mutually Protected; Group Function.

\section{INTRODUCTION}

The primary purpose of teeth is to prepare food for ingestion. Processing food demands the actions of trituration, manipulation, and deglutition. When teeth are lost, the function is compromised [1]. The replacement of missing teeth is accomplished using dental prostheses. These prostheses may be used to replace all the teeth with complete dental prostheses, or some of the teeth with partial dental prostheses. Replacement teeth may gain support using remaining natural teeth, dental implants, residual alveolar ridges, or a combination of these structures. Studies clearly indicate that removable prostheses are not as effective in restoring function, esthetics, and patient self-esteem. In fact, multiple nutritional deficiencies, associated comorbidities, and loss of self-confidence have been reported with removable prostheses [2-4]. Implants may provide single tooth replacement, or they could support the entire dentition with fixed dental prostheses. Although natural teeth and dental implants may provide similar support for dental prostheses, there are substantial differences between the two. The implant is an alloplastic device that replaces the natural tooth root and supports the prosthesis. Although implants may provide aesthetic and comfortable tooth replacement, there are characteristics associated with the use of dental implants that must be considered [5]. Perhaps the most obvious is the lack of a periodontal ligament around implants and thus a lack of micro-mobility during chewing. Consequently, occlusion with dental implants may be at greater risk, especially when teeth contact in lateral excursions [6].

The aim of this review was to identify the most harmonious relationship of prosthetic teeth when supported by dental implants and describe occlusal theories using a systematic review.

Received: July 17, 20211; Revised: August 05, 2021; Accepted: September 03, 2021; Published: September 07, 2021

*Corresponding author: Dr. Mariam Margvelashvili-Malament, Assistant Professor

Department of Prosthodontics, School of Dental Medicine, Tufts University, 1 Kneeland Street, Boston MA 02111, USA

Tel: +1 (617) 636-7000; Fax: +1 (617) 636-6583; e-mail: mariam.malamet@tufts.edu

Copyright: $\odot 2021$ the Editorial Council for the Stomatology Edu Journal. 


\section{MATERIALS AND METHODS}

The research question for this review was formulated following the Preferred Reporting Items for Systematic Reviews and Meta-Analyses (PRISMA) guidelines using the Population, Intervention, Comparison and Outcome (PICO) tool.

POPULATION: The patient group receiving fixed dental prostheses supported by implants.

INTERVENTION: The patient group receiving a specific form of treatment. Unilateral group function lateral occlusion with multiple posterior teeth guiding lateral movements.

COMPARISON: The patient group receiving an alternative form of treatment. Mutual protection placing lateral contacts on anterior teeth thereby separating the posterior teeth during mandibular movements. OUTCOME: The results obtained from the two compared treatments.

In partially and/or completely edentulous patients restored with implant-supported fixed dental prostheses either a mutually protected occlusion, whereby the anterior teeth separate the posterior teeth in laterotrusion, or a group function occlusion, where the anterior and posterior teeth contact simultaneously on the working side result in fewer complications? The dental literature was to be evaluated to determine the relative superiority of one occlusal scheme over the other to answer the PICO question.

An electronic search was conducted utilizing the following database and Software: PubMed and EndNote using the search strategy "(dental implants OR implants) AND Occlusion AND implant restoration AND "dental implants"[Mesh]" and "Dental Occlusion and Dental Implant and Fixed Prosthesis or Occlusion or Group Function and Mutually Protected" respectively. No language or journal type restrictions were applied to the search. A supplemental hand search was also conducted. Search strategy and outcomes for each source are provided in Table 1.

To meet the eligibility requirements, the selected studies had to meet the following inclusion criteria:

1. Human studies.

2. Randomized controlled clinical trials (RCT), clinical trials, systematic reviews.

3. If multiple publications on the same cohort to be found, only the publication with the longest followup time was included.

The exclusion criteria included the following:

1. Not meeting inclusion criteria.

2. Duplicate publications.

3. Full-text not available in English.

4. Full-text unavailable.

5. No information available about occlusal concepts applied.

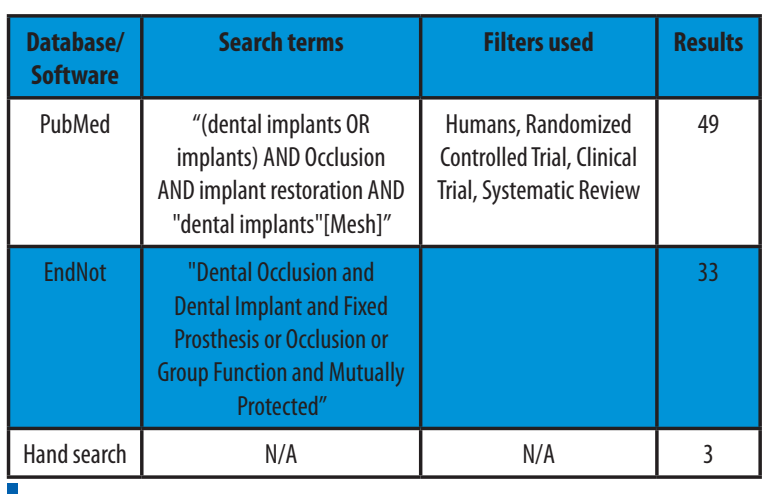

Table 1. Search strategy.

\subsection{Screening Process}

A total of 49 (PubMed) and 33 (EndNote) articles were selected by two of the authors (M.M.M. and S.E) as being of potential interest to the reader on the topic of dental occlusion. These articles were assessed by reviewing the titles and then by reading the abstracts. Any disagreement regarding the quality of the article was managed through discussion and eventually by the inclusion of the third author (K.A.M) if necessary.

The authors, after compilation and assessment of the articles, extracted the available data from the articles and compiled the gathered data. The articles were evaluated relative to the use of natural tooth support or dental implant support of the final prostheses.

\section{RESULTS}

Using the literature search described, no studies were identified to answer the PICO question. There were subjective descriptions of different techniques that were used in the management of clinical patients relative to the posterior fixed occlusal scheme. The PubMed search was linked with 49 articles. After screening the titles, 39 were assessed as irrelevant, 7 as potentially relevant, 2 as hypothetical designs and 1 as relevant. The EndNote search was linked with 33 articles, 23 were reviewed as irrelevant, 7 potentially relevant, 3 represented hypothetical designs (Fig. 1).

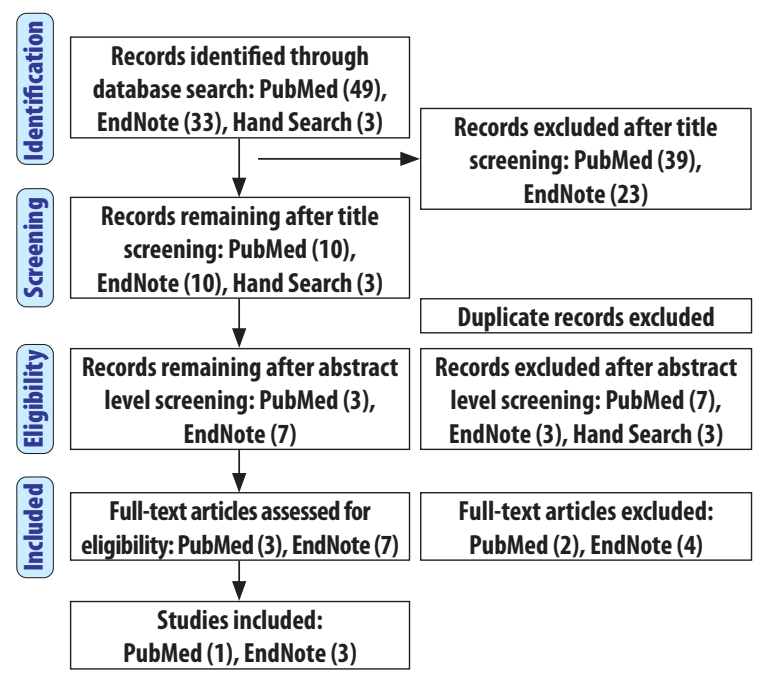

Figure 1. Screening process. 
Dental occlusion described as mutually protected occlusion was identified as the most common method of management of lateral articulation of the teeth. Group function was identified in three articles, although no scientific studies were performed. Due to an inability to identify a study, or studies, that answer the PICO question or provided conceptual homogeneity, no Meta-Analysis or risk of bias assessment could be conducted. The following opinion-based and clinical articles were identified and are summarized in Table 2.

Wismeijer et al. [7] described implant reconstruction in the edentulous mandibular arch opposing an edentulous maxilla as being treated using bilateral balanced occlusion. Mutually protected occlusion or group function was suggested when the maxilla was dentate. In an article that was primarily describing the use of short implants in the posterior areas, Misch et al [8] suggested that cantilevers should be eliminated, and the patient should be restored with a mutually protected or canine guided occlusal concept.

In 2016, Sheridan et al. [9] performed a systematic review that failed to identify evidence in favor of any specific occlusal management. Once again, these authors suggested mutually protected occlusion with anterior guidance with wide freedom in centric and avoidance of cantilevers. Considering the descriptors, specifically with "wide freedom in centric," the readers may have interpreted the terms as fulfilling the description of group function.

Esquivel-Upshaw et al [10] studied the effect of direction and magnitude of occlusal loading on implant supported FDPs. The authors provided group function to the treated patients and identified these lateral excursive contacts as not being associated with a higher fracture occurrence. Conversely, the strong centric contacts resulted in higher porcelain fracture rate. None of the treated patients received mutually protected occlusion. The authors suggested that due to the absence of a periodontal ligament, implant supported fixed dental prostheses should have lighter maximum intercuspation contacts.

\section{DISCUSSION}

This systematic review of the literature failed to identify randomized controlled clinical trials or cohort studies that would promote one specific occlusal design concept over another. Even from the standpoint of descriptive studies there is no clear recommendation. The lack of a periodontal ligament limits the micromotion and proprioceptive capability of implant-supported fixed restorations making them potentially more succeptible to technical complica-tions. Therefore, it is of paramount importance to provide optimal occlusion to hopefully generate higher survival rates for implant-supported fixed restorations. However, the question remains as to what is the optimal occlusal scheme. Although this systematic review failed to identify studies that would answer the question directly, suggestions dervied from the included articles as well as the factors that may be considered confounding variables are further discussed.

Two occlusal concepts that are currently applied to fixed restorations on implants are: group function occlusion and mutually protected occlusion.

Both occlusal approaches share the concept of simultaneous, bilateral contact of posterior teeth when the jaws are in maximum intercuspation. The concepts differ in the way that occlusion of the anterior teeth is described with group function exhibiting very light contact of the anterior teeth while mutual protection entails anterior teeth contact in all excursive movements thereby separating the posterior teeth.

Mutually protected occlusion is considered by many to be the ideal occlusal scheme for the natural dentition. D'Amico described the size and innervation of the canine tooth as a way to explain the rationale for embracing the mutual protection concept [11-13]. Conversely, group function exhibits unilateral, simultaneous anterior and posterior tooth contact as the jaws move laterally from maximum intercuspation. Primary support for the concept of group function is seen when the dentition exhibits abrasive wear after years of function [14-18].

Although without clear scientific or clinical evidence, three of the selected four studies recommended mutually protected occlusion for implant-supported fixed restorations.

Most of the authors highlight the complexity of biomechanics with implant-supported fixed dental prostheses. Misch et al. suggested decreasing stress through a biomechanical approach, namely: splinting implants and avoiding cantilevers, applying

\begin{tabular}{|c|c|c|c|c|c|c|c|}
\hline Author/Year & Journal & $\begin{array}{c}\text { Study } \\
\text { Design }\end{array}$ & $\begin{array}{c}\text { Sample Size } \\
\text { (number of FDPs }\end{array}$ & $\begin{array}{c}\text { Occlusal } \\
\text { Concept Used }\end{array}$ & $\begin{array}{c}\text { Observation } \\
\text { Time }\end{array}$ & $\begin{array}{c}\text { Prostheses' } \\
\text { Survival Rate (\%) }\end{array}$ & Results \\
\hline $\begin{array}{c}\text { Wismeijer, D. et } \\
\text { al 1995 }\end{array}$ & $\begin{array}{c}\text { Journal of } \\
\text { Prosthetic Dentistry }\end{array}$ & Review & $\mathrm{N} / \mathrm{A}$ & $\mathrm{N} / \mathrm{A}$ & $\mathrm{N} / \mathrm{A}$ & $\mathrm{N} / \mathrm{A}$ & $\begin{array}{c}\text { Recommends mutually protected } \\
\text { occlusion }\end{array}$ \\
\hline $\begin{array}{c}\text { Misch, C. E. } \\
\text { et al 2006 }\end{array}$ & $\begin{array}{c}\text { Journal of } \\
\text { Periodontology }\end{array}$ & $\begin{array}{c}\text { Retrospective } \\
\text { Case Series }\end{array}$ & 338 & $\begin{array}{c}\text { Mutually } \\
\text { protected }\end{array}$ & Up to 6years & $\mathrm{N} 98.9 \%$ & $\begin{array}{c}\text { Recommends methods to decrease } \\
\text { biomechanical stress (including } \\
\text { mutually protected occlusion) }\end{array}$ \\
\hline $\begin{array}{c}\text { Sheridan, R. A. } \\
\text { et al 2016 }\end{array}$ & Implant Dentistry & Review & $\mathrm{N} / \mathrm{A}$ & $\mathrm{N} / \mathrm{A}$ & $\mathrm{N} / \mathrm{A}$ & $\mathrm{N} / \mathrm{A}$ & $\begin{array}{c}\text { Recommends mutually protected } \\
\text { occlusion }\end{array}$ \\
\hline $\begin{array}{c}\text { Esquivel-Upshaw, } \\
\text { F. H. et al 20146 }\end{array}$ & Journal of Dentistry & RCT & 89 & Group Function & 3 years & $85 \%$ & Recommends light centric contacts \\
\hline
\end{tabular}

Table 2. Included studies. 
a mutually protected occlusal concept, and selecting an implant design to increase bone-to-implant contact area. Unfortunately, this study lacked a control group utilizing an alternative occlusal concept. Mutually protected occlusion resulted in high survival rates, yet the study does not answer the PICO question of current systematic review. It shows successful application of this occlusal concept but fails to demonstrate its superiority [8].

Esquivel-Upshaw, et al. showed no risk of higher fracture of implant-supported fixed dental prosthesis in excursive contacts (group function). This was true for both metal-ceramic and ceramic-ceramic restorations. However, similarly to Misch there was no control group of the alternative occlusal concept group. Regardless, the authors recommend hypoocclusion in maximum intercuspation on implant-supported fixed restorations [10].

Another concept that should be mentioned is bilateral balanced occlusion. Unlike mutually protected occlusion and group function, bilateral balance provides bilateral contacts in eccentric movements. While this occlusal concept is popular in complete denture prosthodontics, it should also be considered when a fixed restoration opposes a removable complete denture. When a prosthodontist considers the alternative occlusal concepts for treating edentulous pateints with fixed prostheses, the decision is often made based upon clincal experience and personal and laboratory preferences. However, another important aspect that should be considered is the type of restorative material being used. Normally the material choices are acrylic resin, cast metal, metal-ceramic, and milled or pressed ceramic materials. Over time, the use of acrylic resin has diminished because of unfavorable wear characteristics. Although acrylic resin prostheses usually have a supporting metal substructure, the wear characteristics of acrylic or composite materials as an occlusal material demonstrate moderate to severe wear in a relatively short period of time. The prostheses can be removed and the surface veneering material replaced, but this will require a number of appointments that will incur some cost. In addition, the customization of the occlusal surface of the prosthesis may create an occlusal awareness for the patient that could be unfavorable.

Full cast metal restorations could certainly be considered. The advantage of cast metal is that most cast materials exhibit a hardness and a wear pattern similar to that seen with natural dentition. The disadvantage of cast metal is the appearance and the relatively high cost associated with such a prostheses. In today's esthetically conscious society, full cast metal restorations are unlikely to prove acceptable. Metal ceramic restorations have been one of the most popular choices for restorative material for more than 50 years. Metal ceramic is relatively stable over time although it is somewhat prone to chipping and fracture of the veneering ceramic material. The restoration, because of the fabrication process, is built up incrementally. The ability to duplicate a prosthesis sometime after it was made originally will provide a cosmetic benefit for the patient but in terms of full functional replacement, the incremental stacking of porcelain will never be so accurate that it could be used without adjustment. In addition to the abrasive nature of metal ceramic restorations there is also a tendency for the material to lose surface detail over time. The cost of metal ceramic is dependent upon the type of metal alloy that is used. This is a material that was quite popular through the first decades of implant dentistry but it appears to have lost much of the previous popularity of this material.

The use of milled, or pressed, all ceramic materials has demonstrated a number of advantages. Since the design of such a prosthesis (milled) can be saved digitally, any future damage in the form of breakage, could be easily restored as long as the fixed dental prosthesis is retrievable. Perhaps a more important advantage is that monolithic all ceramic materials exhibit very little, if any, discernible wear over time. With the advent of lithium disilicate and zirconia materials the aesthetic replacement of posterior teeth should be easy to achieve and reliable and predictable into the future. Assuming that the choice of material will be that of a milled all ceramic material, it is important to remember the unique characteristics of the dental implant that must be duplicated or compensated for in the final prosthesis. Perhaps the most critical factor as it relates to implants is the relative immobility of the individual implants. Unlike natural teeth that exhibit physiologic mobility, implants are, for all intents and purposes, rigid within bone. This rigid device must have a carefully controlled occlusal relationship with the opposing teeth. The patient can advise the clinician of the presence of high occlusal contacts but it is very hard to communicate to the patient the more important factor related to lateral motions and how those must be compensated in the prosthetic design.

\section{CONCLUSIONS}

Within the limitations of this systematic review the authors agreed on the following conclusions:

- There is lack of information as to which occlusal scheme, mutually protected or group function, is more favorable.

- Based upon clinical preference and experience, group function or mutually protected occlusion, both appear to be acceptable occlusal schemes for implant supported fixed dental prostheses.

- Future clinical studies are needed to assess scientific and clinical evidence of the superiority of one occlusal scheme over other.

\section{AUTHOR CONTRIBUTIONS}

MM-M: was responsible for the conceptualization, design, data analyses and writing the manuscript. SE: was responsible for the conceptualization, design, and data analyses, and editing the manuscript. KM: was responsible for editing the manuscript. All the authors gave their final approval and agreed to be accountable for all aspects of the work. 


\section{REFERENCES}

1. Curtis DA, Plesh O, Miller AJ, et al. A comparison of masticatory function in patients with or without reconstruction of the mandible. Head Neck. 1997 Jul;19(4):287-296. doi: 10.1002/ (sici) 1097-0347(199707)19:4<287:aid-hed7>3.0.co;2-x. PMID: 9213107.

CrossRef PubMed Google Scholar Scopus

2. Felton DA. The ACP's evidence-based guidelines for the care and maintenance of complete dentures. J Prosthodont. 2010 Dec;19(8):591. doi: 10.1111/j.1532-849X.2010.00662.x. PMID: 21129079.

Full text links CrossRef PubMed Google Scholar Scopus

3. Felton DA. Edentulism and comorbid factors. Tex Dent J. 2010

Apr;127(4):389-401. PMID: 20446489.

Full text links CrossRef PubMed Google Scholar Scopus WoS

4. Felton DA. Complete edentulism and comorbid diseases: an update. J Prosthodont. 2016 Jan;25(1):5-20. doi: 10.1111/ jopr.12350. Epub 2015 Sep 15. PMID: 26371954.

Full text links CrossRef PubMed Google Scholar Scopus WoS 5. Buser D, Sennerby L, De Bruyn H. Modern implant dentistry based on osseointegration: 50 years of progress, current trends and open questions. Periodontol 2000. 2017 Feb;73(1):7-21. doi: 10.1111/prd.12185. PMID: 28000280.

Full text links CrossRef PubMed Google Scholar Scopus WoS 6. Koyano K, Esaki D. Occlusion on oral implants: current clinical guidelines. J Oral Rehabil. 2015 Feb;42(2):153-161. doi: 10.1111/ joor.12239. Epub 2014 Oct 6. PMID: 25284468.

Full text links CrossRef PubMed Google Scholar Scopus WoS 7. Wismeijer D, van Waas MA, Kalk W. Factors to consider in selecting an occlusal concept for patients with implants in the edentulous mandible. J Prosthet Dent. 1995 Oct;74(4):380-384. doi: 10.1016/s0022-3913(05)80378-6. PMID: 8531156.

Full text links CrossRef PubMed Google Scholar Scopus WoS 8. Misch CE, Steignga J, Barboza E, et al. Short dental implants in posterior partial edentulism: a multicenter retrospective 6-year case series study. J Periodontol. 2006 Aug;77(8):1340-1347. doi: 10.1902/jop.2006.050402. PMID: 16937587.

Full text links CrossRef PubMed Google Scholar Scopus WoS 9. Sheridan RA, Decker AM, Plonka AB, Wang HL. The role of occlusion in implant therapy: a comprehensive updated review. Implant Dent. 2016 Dec;25(6):829-838. doi: 10.1097/ ID.0000000000000488. PMID: 27749518.

Full text links PubMed Google Scholar Scopus WoS
10. Esquivel-Upshaw JF, Mehler A, Clark AE, et al. Fracture analysis of randomized implant-supported fixed dental prostheses. J Dent. 2014 Oct;42(10):1335-1342. doi: 10.1016/j. jdent.2014.07.001. Epub 2014 Jul 9. PMID: 25016139; PMCID: PMC4169735.

Full text links CrossRef PubMed Google Scholar Scopus WoS 11. Alexander PC. The periodontium and the canine function theory. J Prosthet Dent. 1967 Dec;18(6):571-578. doi: 10.1016/0022-3913(67)90223-5. PMID: 5234942.

Full text links CrossRef PubMed Google Scholar Scopus

12. D'Amico A. The canine teeth-normal functional relation of the natural teeth of man. J South Calif Dent Assoc. 1958;26(1):6-23. Google Scholar

13. D'Amico A. Functional occlusion of the natural teeth of man. J Prosthet Dent. 1961;11(5):899-915. https://doi. org/10.1016/0022-3913(61)90148-2

Google Scholar Scopus

14. Becker CM, Kaiser DA. Evolution of occlusion and occlusal instruments. J Prosthodont. 1993 Mar;2(1):33-43. doi: 10.1111/j.1532-849x.1993.tb00379.x. PMID: 8374710.

Full text links CrossRef PubMed Google Scholar Scopus

15. Jemt T, Lundquist S, Hedegard B. Group function or canine protection. J Prosthet Dent. 1982 Dec;48(6):719-724. doi: 10.1016/ s0022-3913(82)80036-x. PMID: 6961212.

Google Scholar

16. Schwartz H. Occlusal variations for reconstructing the natural dentition. J Prosthet Dent. 1986 Jan;55(1):101-105. doi: 10.1016/0022-3913(86)90084-3. PMID: 3511222.

Full text links CrossRef PubMed Google Scholar Scopus WoS 17. Thornton LJ. Anterior guidance: group function/canine guidance. A literature review. J Prosthet Dent. 1990 Oct;64(4):479482. doi: 10.1016/0022-3913(90)90048-h. PMID: 2231460. Full text links PubMed Google Scholar Scopus

18. O'Leary TJ, Shanley DB, Drake RB. Tooth mobility in cuspidprotected and group-function occlusions. J Prosthet Dent. 1972 Jan;27(1):21-25. doi: 10.1016/0022-3913(72)90169-2. PMID: 4550061 .

Full text links PubMed Google Scholar Scopus

\section{Mariam MARGVELASHVILI-MALAMENT}

DMD, MSc, PhD, Assistant Professor Department of Prosthodontics School of Dental Medicine Tufts University - TUSDM Boston, MA, USA

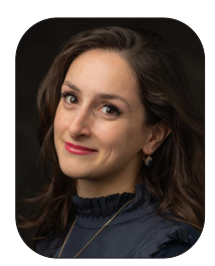

Dr. Margvelashvili-Malament is an Assistant Professor in the Department of Prosthodontics at Tufts University School of Dental Medicine (TUSDM). She is a Diplomate of the American Board of Prosthodontics and Fellow of the American College of Prosthodontics.

She received her DMD from the Tbilisi State University in Georgia, Master of Science and PhD Degrees in Dental Materials from the University of Siena, Italy. She is a co-author of the national residency program in Prosthodontics in Georgia. She was also the Founding Chair of the International Dental Program at the University of Georgia.

She is the recipient of an ITI Scholarship. She completed her Advanced Graduate training in Prosthodontics at TUSDM with high honors. She has lectured internationally and published numerous scientific articles and she also serves as a reviewer for international journals. 


\section{Questions}

\section{How can mutually protected occlusal concept be described?}

$\square$ a. An occlusal scheme in which the posterior teeth prevent excessive contact of the anterior teeth in maximal intercuspal position, and anterior teeth disengage the posterior teeth in all mandibular excursive movements;

Db. An occlusal scheme in which multiple posterior teeth contact in all mandibular excursive movements on the working side to distribute occlusal forces;

Dc. An occlusal scheme in which the buccal and lingual cusps of the maxillary posterior teeth on working and balancing side contact buccal and lingual cusps of mandibular posterior teeth in all mandibular excursive movements;

$\square$ d. None of the above.

\section{How can group function occlusal concept be described?}

$\square$ a. An occlusal scheme in which the posterior teeth prevent excessive contact of the anterior teeth in maximal intercuspal position, and anterior teeth disengage the posterior teeth in all mandibular excursive movements;

Db. An occlusal scheme in which multiple posterior teeth contact in all mandibular excursive movements on the working side to distribute occlusal forces;

Dc. An occlusal scheme in which the buccal and lingual cusps of the maxillary posterior teeth on working and balancing side contact buccal and lingual cusps of mandibular posterior teeth in all mandibular excursive movements;

$\square d$. None of the above.

\section{Slightly hypo-occlusion in maximal intercuspal contacts is recommended for implant-supported fixed restorations because:}

$\square$ a. The lack of a periodontal ligament limits the micromotion;

ab. The lack of a proprioceptive capability of implant-supported fixed restorations;

$\square$ c. Both a. and b. are correct;

$\square$ d. None of the above.

\section{Based on the findings of this systematic review, the following is correct:}

$\square$ a. There is a lack of information as to which occlusal scheme, mutually protected or group function, is more favorable for implant-supported fixed restorations. Group function or mutually protected occlusion, both appear to be acceptable occlusal schemes;

$\square$ b. There is strong scientific evidence that suggests the use of group function occlusal concept for implant-supported fixed restorations;

$\square$ c. There is strong scientific evidence that suggests the use of mutually protected occlusal concept for implant-supported fixed restorations;

$\square$ d. None of the above. 